\title{
Oropharyngeal colonization: epidemiology, treatment and ventilator-associated pneumonia prevention
}

\author{
Jonathan Messika ${ }^{1,2,3}$, Béatrice La Combe ${ }^{1,2,3,4}$, Jean-Damien Ricard ${ }^{1,2,3}$ \\ ${ }^{1}$ Medical-Surgical Intensive Care Unit, Hôpital Louis Mourier, AP-HP, Colombes, France; ${ }^{2}$ Univ Paris Diderot, Sorbonne Paris Cité, IAME, UMR \\ 1137, Paris, France; ${ }^{3}$ INSERM, IAME, UMR 1137, Paris, France; ${ }^{4}$ Intensive Care Unit, Lorient Hospital, Lorient, France \\ Contributions: (I) Conception and design: All authors; (II) Administrative support: None; (III) Provision of study materials or patients: None; (IV) \\ Collection and assembly of data: All authors; (V) Data analysis and interpretation: All authors; (VI) Manuscript writing: All authors; (VII) Final \\ approval of manuscript: All authors. \\ Correspondence to: Dr. Jonathan Messika, MD, PhD. Medical-Surgical Intensive Care Unit, Hôpital Louis Mourier, 178 rue des Renouillers, F-92700, \\ Colombes, France. Email: jonathan.messika@aphp.fr.
}

\begin{abstract}
Oropharyngeal (OP) colonization and ventilator-associated pneumonia (VAP) mechanisms are tightly linked. A significant within-population variation in OP colonization has been described, with its composition being dependent from patients' severity. For instance, healthy subjects have a very low rate in Gram-negative bacteria (GNB) colonization, while its rate rises in comorbid patients, reaching high proportions in ICU patients. Various factors can be put forward to explain the modifications of hospital acquired OP. ICU patients might suffer from underlying diseases; the gastric reflux induced by the presence of nasogastric tubes and the patients' position influences OP colonization; salivary composition might influence OP content, as it modulates bacterial adhesion and induces reversible bacterial changes enhancing bacterial binding. The transition from OP colonization to VAP has been shown in numerous studies, with the digestive tract acting as a filter, or as a reservoir. Some therapies have been investigated to modulate OP colonization, in order to reduce the risk for VAP. Among those, mammalian antimicrobial peptides have been shown effective in reducing GNB colonization in healthy subjects, but failed in preventing VAP in ICU patients. The widely used chlorhexidine was tested in numerous trials. Data on its efficacy are conflicting, and meta-analyses yield discordant results. Above all, several drawbacks have aroused: a poor tolerance of concentrated solutions; an increased risk of death in the less severe patients; and a reduced susceptibility towards chlorhexidine of number of VAP pathogens. Proanthocyanidins, used to prevent Escherichia coli adhesion to the urothelium, have been tested in mice model of pneumonia with interesting results. Some complementary data are needed before moving to clinical research. Future research paths should include a reappraisal of OP colonization; finding better formulations for chlorhexidine; define the best populations to target oral decontamination and developing other strategies to prevent and treat OP colonization.
\end{abstract}

Keywords: Oropharyngeal colonization; ventilator-associated pneumonia (VAP); chlorhexidine

Submitted Sep 17, 2018. Accepted for publication Oct 06, 2018.

doi: $10.21037 / \mathrm{atm} .2018 .10 .17$

View this article at: http://dx.doi.org/10.21037/atm.2018.10.17

\section{Within-population variations of the oropharyngeal (OP) colonization}

Fifty years ago, one of the first studies on OP colonization assessed its composition in 5 different populations (1). OP samples were studied in healthy subjects, and in 4 types of in-hospital patients with varying degrees of illness severity. In this study, Johanson et al. showed that the frequency of Gram-negative bacteria (GNB) colonization was linked to patients' illness severity (1). To date, results from this study stand and have not been replicated with the same completeness. 


\section{OP colonization in bealthy subjects}

Normal bacterial flora of the oropharynx comprises mainly anaerobes bacteria and $\alpha$-haemolytic streptococci (Streptococcus viridans and S. mitis) $(2,3)$. Studies have shown that the relative distribution of species may vary within the oral cavity and within individuals (2). Recent studies have also shown a clear difference in the composition between healthy subjects and individuals with periodontal diseases (4). Some pathogenic bacteria can be retrieved, such as Staphylococcus aureus, S. pyogenes, S. pneumoniae, Branhamella catarrbalis, and Neisseria sp. $(2,3,5)$. Across time, various studies focused on GNB OP colonization in healthy subjects, that yielded results very similar to those initially reported $(1,6,7)$. Johanson et al. (1) specifically reported GNB colonization. Healthy subjects were 82 Dallas firemen, and 47 healthcare providers who had not been exposed to antibiotics in the previous 15 days. Interestingly, when a single OP sampling was performed in these subjects, only $2 \%$ had GNB colonization. When multiple samples were performed, at least one was positive for GNB in $6 \%$ of cases. More recently, 101 US healthy soldiers were sampled at three different sites (7) (nares, oropharynx, and groin). Again, GNB OP colonization was noted in only four patients (4\%). These consistent results contrast with those from another study that included 120 healthy subjects (6) and reported a much higher rate: $35.8 \%$ of the subjects had at least one sample with GNB colonization. However, the rate of GNB carriage on two consecutive samples was $6.6 \%$. Noticeably, 2/3 of the subjects were healthcare workers (40 nurses and 40 laboratory-associated persons), which may explain the higher rate of GNB colonization in this population.

\section{The composition of OP colonization is dependent of patients' severity of illness}

Various groups of patients have been surveyed for their OP colonization, alongside healthy adults. When comparing patients from various wards Johanson et al. (1) evidenced a similar rate of GNB OP colonization in psychiatry patients, and in healthy subjects ( $6 \%$ for those who had repeated OP sampling), it reached $16 \%$ in surgical patients when they were sampled only once (and 35\% when repeatedly sampled), and $57 \%$ in moribund patients (and $73 \%$ when repeatedly sampled). In a similar manner, Mackowiak et al. (8) were interested in studying out-patient subjects considered to be "at-risk" for aspiration. Heavy-alcohol drinkers and diabetic had close GNB colonization rates (respectively $35 \%$ and $36 \%$ of GNB colonization on a single sample). Their rate of GNB colonization rate was higher than those from epileptic patients (17\%), drug-addicts (20\%) or healthy subjects (18\%). Other types of patients have been surveyed for their GNB OP colonization. Patients with chronic obstructive pulmonary disease (COPD) $(6,9)$ have been shown to harbour a higher rate of GNB colonization than healthy subjects (9); and the greater the severity of their disease, the higher the prevalence. Likewise, elderly patients have been shown to have a high rate of GNB OP colonization $(10,11)$, ranging from $20.5 \%$ to $43 \%$. Even though these studies had similar ranges of ages, other variables were not comparable, as their dependency level or their comorbid conditions which were not equivalent.

Interesting data stem from Filius et al. study (12). In this prospective epidemiological survey, the authors screened the OP (and the digestive) colonization of 200 ICU and 319 general wards patients at admission, discharge from ICU and hospital, and at 1 and 3 months after discharge. If the GNB OP colonization rate was extremely low at general ward admission $(1.1 \%)$, it significantly increased during hospital stay, to $12.4 \%$, and remained high at 1 and 3 months of hospital discharge (respectively $19.4 \%$ and $20.3 \%$ ). This study confirms that general wards patients are less prone to have GNB OP colonization at admission, while it colonizes the OP during hospital stay and persists after discharge. Data on ICU patients will be discussed later.

\section{OP colonization in ICU patients}

Several studies (see Table 1) assessed OP colonization [or dental plaque, which composition is close (3)] in ICU patients, mostly in its relationship with ventilatorassociated pneumonia. Since the study of Johanson et al. (1), in which the most severe patients were "moribund" but not necessarily hospitalized in the ICU, OP colonization incidence with pathogenic bacteria is reported to range from $23 \%$ and $96 \%$ at ICU admission. Between $36 \%$ and $100 \%$ of ICU admitted patients acquire OP colonization during their stay (13-20). GNB represent an important part of these species $(32-41 \%)(14,19)$, Enterobacteriaceae being the predominant type (20\% of the samples) (15) [Klebsiella pneumoniae, 13-18\% $(13,15,16)$; Citrobacter sp. $23 \%$ (16)], followed by non-fermenting GNB (Pseudomonas aeruginosa, 11-32\%) (13,15-17,19). But Gram-positive 


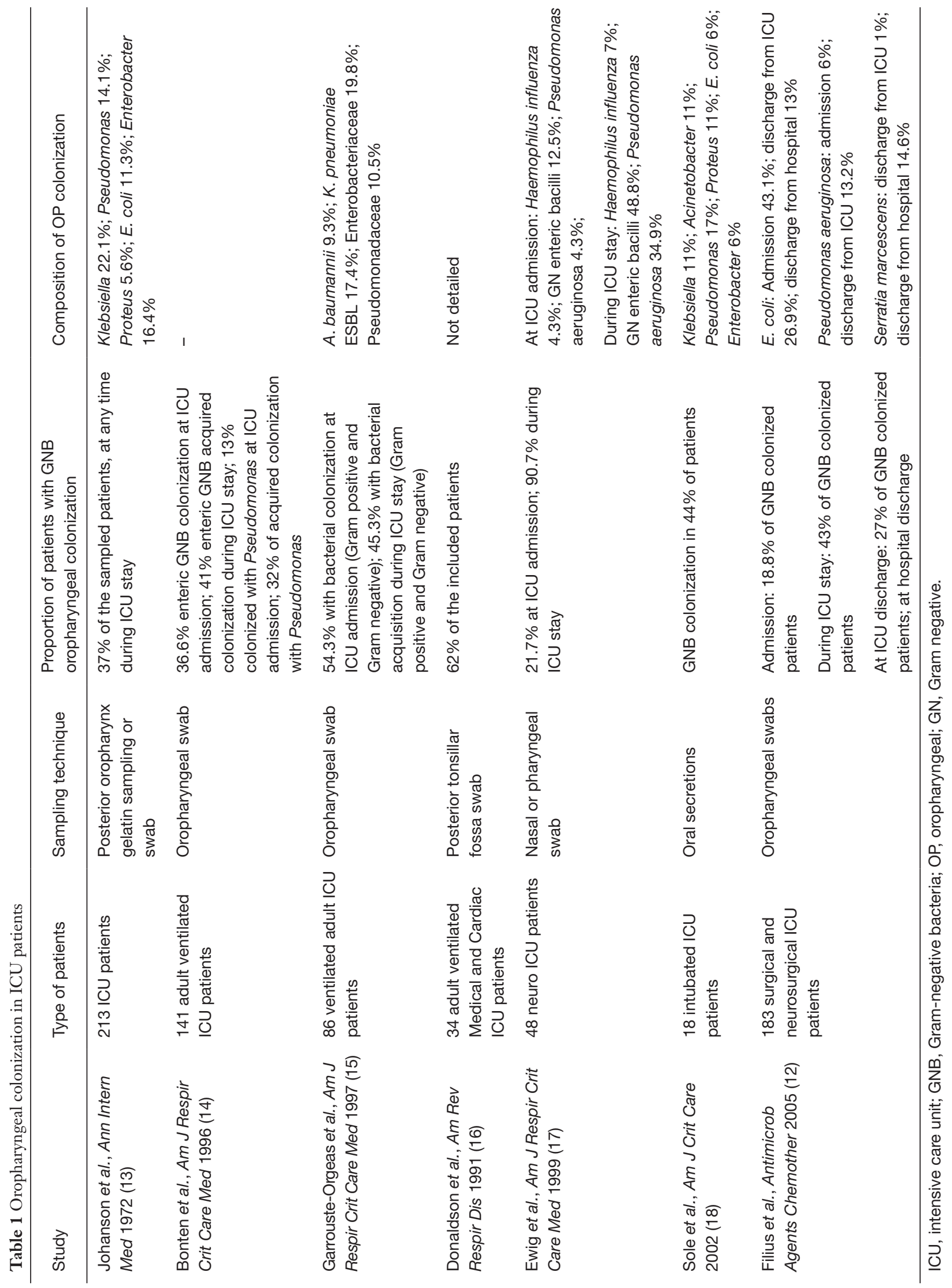


cocci also plays an important part in OP colonization, with Staphylococcus aureus reported in 15\% to $78 \%(15,18-20)$, or Streptococcus sp. in 44\% (18). The dynamics of GNB OP colonization are studied by Filius et al. (12). The authors report an increasing GNB OP colonization rate during ICU hospitalization (from $18 \%$ to $27 \%$ ), and, again, a persistence of this colonization was evidenced at 1 and 3 months after discharge. This elegant study shows a significant decrease in E. coli OP colonization during ICU stay (from $43.1 \%$ at admission, to $26.9 \%$ at discharge), with a novel ascend after one month to $28.3 \%$; and a significant increase in $P$. aeruginosa from $6 \%$ to $13.2 \%$ that persisted after hospital discharge.

These wide ranges of incidence result from heterogeneity among these studies:

* First, all these data were obtained using different sampling methods and sites: either the dental plaque (20), or OP swabbing (12-16), both (19), or sampling of salivary secretions (18). All these sites have been considered to be similar in a recent study of OP colonization sampling in five healthy subjects (3), but whether this equivalence is also true in ICU patients with GNB OP colonization has not been assessed;

* Next, one has to bear in mind that OP hygiene might not have been similar in all the patients included in these studies. We reported some years ago in a European survey that only $48 \%$ of surveyed ICU European caregivers reported using oral chlorhexidine rinses routinely (21);

* Last, microbiologic data varied among studies, some focused on GNB only (14), others added Gram-positive cocci (15), while others studied OP colonization epidemiology in a very comprehensive way $(19,20)$.

To summarize, it seems clear that, although its magnitude may vary from one study to another, changes in OP colonization affect a much greater proportion of patients in the ICU than in other wards. The reason behind these differences and the pathophysiology of these changes are now to be discussed.

\section{Why such a modification of hospital acquired OP colonization?}

Various factors can be put forward to explain the modification of hospital acquired OP colonization. If they are true for general wards, we will focus on ICU conditions.

\section{Impact of underlying disease and treatments}

As discussed earlier, some comorbid conditions are associated with a higher burden of GNB OP colonization $(1,6,8,9)$. One has to bear in mind that the presence of a comorbid condition is note rare in ICU patients $(22,23)$, and that nearly two-thirds of ICU patients receive antimicrobials treatments (22), which might play a part in OP colonization modification.

\section{The influence of ICU care}

The frequency of gastric reflux is promoted by the presence of nasogastric tubes, suctioning material or orotracheal intubation (18,24). Aspiration of gastric content is enhanced by the supine position, may it be even semi-recumbent position. For instance, Torres et al. (25) showed, in 19 intubated patients, that aspiration of the gastric content existed when patients were in semi-recumbent position, although reduced compared to strictly supine position. Gastric content was labeled with technetium-99m sulphur colloids, and samples of endobronchial secretions were obtained and radioactive counts were performed, in supine or semi-recumbent positions. The study showed that radioactive patterns were higher in patents in supine position, but not null in semi-recumbent position. Interestingly, the patients in semi-recumbent position had the same micro-organism isolated in the stomach, the $\mathrm{OP}$ and the bronchial sample in $32 \%$, while it accounted for $68 \%$ in patients in the supine position.

Furthermore, healthcare workers are known to be vectors of the cross-contamination and colonization $(24,26)$.

\section{Salivary modifications}

Salivary composition might influence OP bacterial content. Various factors affect OP colonization. For instance, $K$. pneumoniae adhesion to buccal cells has been shown to be increased with a decrease in salivary $\mathrm{pH}$ and a decrease in salivary output (27). Likewise, Dal Nogare et al. performed measurements of salivary elastase, fibronectin [a protein known to inhibit GNB adhesion to epithelial cells (28)], fibronectin digestive activity, and GNB OP colonization in cardiac surgery post-operative patients (29). Fibronectin digestive activity and salivary elastase concentration were significantly increased in patients in whom GNB colonization appeared (29), in comparison to those in whom it did not. 
Among mechanisms enhancing bacterial adhesion to epithelial cells, phase variation is of particular interest. It results in a reversible change in virulence factors according to the environmental situation and the needs of the bacteria (30). It involves surface antigens, such as lipopolysaccharides, capsule or glycosylated pili, with importance in colonization process, and in the binding of the bacteria to the epithelial cell.

These data concur to explain the proneness to the modification of the OP colonization in ICU patients. The link between OP colonization and VAP will now be discussed.

\section{OP colonization and VAP pathogens are tightly linked}

The first reports linking OP colonization and VAP epidemiology were made by Johanson et al. (13), more than 45 years ago. Since then, various reports confirmed this tight link, some including the involvement of the digestive tract, that acts either as a filter or as a reservoir $(14,15)$. This link between the 3 sites will be detailed thereafter.

In their pioneer study, Johanson et al. (13) included 213 ICU patients. These were repeatedly sampled in the oropharynx and the respiratory tract. The authors therefore show that the GNB OP colonization was a risk factor for the occurrence of VAP with the same pathogen: $23 \%$ of the patients with a GNB OP colonization evolved towards a confirmed VAP, with the same pathogen; whereas a VAP occurred in only $3.3 \%$ of OP colonization-free $(\mathrm{P}<0.0001)$.

When focusing on gastric and OP colonization in 141 patients receiving mechanical ventilation, Bonten et al. (14) described a significant increase in the risk of VAP for Enterobacteriaceae and Pseudomonas aeruginosa. A higher risk of VAP was associated with the presence of an Enterobacteriaceae in the OP colonization either at admission, or during ICU stay (with, respectively, $\mathrm{OR}=3.41 ; \mathrm{P}=0.03$ and $\mathrm{OR}=3.41 ; \mathrm{P}=0.04)$. Likewise, $P$. aeruginosa VAP was significantly associated with its ICU acquired gastric $(\mathrm{OR}=7.68 ; \mathrm{P}=0.006)$ or $\mathrm{OP}$ colonization $(\mathrm{OR}=11.59 ; \mathrm{P}<0.00001)$.

In a study focusing in 48 neuro-trauma patients, Ewig et al. (17) showed that prior nasal or OP colonization with Streptococcus pneumoniae, Staphylococcus aureus and Haemophilus influenzae was an independent risk factor for tracheal colonization, and subsequent early-onset VAP. Data of GNB colonization were less univocal as VAP risk did not significantly increase with GNB OP colonization.
Nevertheless, GNB tracheal and OP colonization were low at ICU admission (respectively 10\% and 16\%) and significantly increased during follow-up (49\% and 58\%). It has to be underlined that a GNB gastric colonization existed at ICU admission for $39 \%$ of the patients, and rose to $60 \%$ during ICU stay. Finally, the presence of a GNB at any time in the gastric or OP colonization was predictive of lower respiratory tract colonization with the same pathogen.

Garrouste-Orgeas et al. (15) went further in identifying the genetic identities of gastric, OP colonization and VAP retrieved GNB. Eighty-six invasively ventilated patients were included. They underwent microbiological samplings from gastric and OP colonization. Pulse-field gel electrophoresis was used in order to compare the genetic identities of the collected bacteria in the different sites. Among the 36 VAP episodes, occurring in 29 patients, the OP colonization and VAP electrophoretic pattern were similar in 17 episodes; for VAP, gastric and OP colonization for 6 episodes; and for VAP and gastric colonization for one of those. Thereafter, in two-thirds of the episodes (24/36) a similar genetic pattern was evidenced between the aerodigestive colonization and VAP causative pathogen.

More recently, our group focused on Escherichia coli VAP and lower respiratory tract colonization (31). We prospectively sampled 132 ventilated patients at rectal, OP and respiratory sites, and studied E. coli isolates of the 25 who harboured E. coli colonization at three sites. We interestingly showed that when E. coli was present in a respiratory sample, E. coli was always present in the OP colonization sample, and that the proportion of virulent extra-intestinal isolates increased from rectal colonization to respiratory sample.

The link between digestive, OP colonization and subsequent pulmonary infection is clearly established. OP colonization is therefore a key site in order to limit and prevent VAP occurrence, with therapies aiming in modulating and reducing the OP bacterial burden. Some therapies have or are currently being investigated.

\section{What therapies to modulate OP colonization?}

\section{Mammalian antimicrobial peptides}

Among mammalian antimicrobial peptides, protegrins have been identified as having an unusually broad spectrum of antimicrobial activity against Gram-positive and Gramnegative bacteria, fungi and some enveloped viruses $(32,33)$. They have been found to be effective in reducing GNB OP 
colonization prevalence and the density of Gram-positive bacterial load in OP colonization of healthy subjects (32). Iseganan is a synthetic protegrin analog, which was tested in immunocompromised patients, undergoing stomatotoxic chemotherapies. It significantly reduced stomatitisassociated symptoms in a phase III randomized controlled trial (34). But the hopes placed in this antimicrobial peptide to reduce the incidence of VAP in the ICU were not confirmed by the only published large randomized controlled trial (35). In this trial, Kollef et al. allocated 709 ventilated patients to receive either oral topical iseganan or a placebo. This study was stopped prematurely for futility, before the inclusion of the 900 planned patients: no difference in VAP occurrence, in day-14 survival or in adverse effects was evidenced. These disappointing data led to the abandon of iseganan as a preventive treatment for VAP.

\section{Chlorbexidine}

This widely used antiseptic $(21,36,37)$ increases the bacterial cell wall permeability, leading to bacterial lysis (38). Its activity encompasses Gram-positive and -negative bacteria [with Gram positive being more susceptible (39-42)], facultative anaerobes, aerobes, yeasts and some viruses $(38,40)$.

Data on its efficacy in preventing VAP during oral care are conflicting. Various meta-analyses were performed, with discordant results summarized below (43-48), and in Table 2 .

\section{No effect on VAP prevention}

Pineda et al. (46) performed a meta-analysis of four studies, gathering the data from 1,202 ventilated patients, from $2 \mathrm{ICU}$, and 2 cardiac surgery post-operative care unit. In this meta-analysis, no significant effect of chlorhexidine oral care was evidenced in the incidence of nosocomial pneumonia, mortality rate, duration of mechanical ventilation and ICU length of stay. The trials included in this meta-analysis had several confounding factors. Among those, the heterogeneity in both control arms (indistinguishable placebos, standard oral care or Listerine), and intervention arms $(0.2 \%$ or $0.12 \%$ chlorhexidine; bi- or thrice-daily; oral rinse or gel) might have blurred any effect.

\section{Effective in VAP prevention but not on mortality}

A larger meta-analysis (45) followed the latter. Seven RCTs were included, resulting in 1,650 patients. The comparators used in these seven trials were placebo for four studies; standard oral care for 2; and Listerine in one. In this second meta-analysis, a significant effect of chlorhexidine was evidenced in reducing VAP, with a relative risk (RR) of 0.74 (95\% CI, 0.56-0.96; $\mathrm{P}=0.03$ ) when using a fixed effect model. Nevertheless, the RR reduction lost significance when using a random effect model (RR 0.7; 95\% CI, $0.48-1.04 ; \mathrm{P}=0.08$ ); furthermore, no effect on mortality was found, rending questionable the use of chlorhexidine to prevent a non-severe ICU adverse event.

The most recent meta-analysis, by Hua et al. (48) gathered 38 RCTs, 18 of those were conducted with chlorhexidine, accounting for 2,451 participants. In this meta-analysis, chlorhexidine significantly reduced the risk for VAP, with a RR of 0.74 (95\% CI, 0.61-0.89; $\mathrm{P}=0.004$ ). But again, no difference in mortality, of mechanical ventilation, or of length of ICU stay was evidenced.

\section{Efficacy depending of chlorhexidine dosage}

Labeau et al. (43) performed a meta-analysis of 14 studies (12 of those investigating chlorhexidine). They interestingly showed that, if the global analysis was in favour chlorhexidine in reducing VAP with a risk reduction of 0.72 (95\% CI, 0.55-0.88; $\mathrm{P}=0.004)$, this effect was limited to chlorhexidine $2 \%$ (RR 0.53 ; 95\% CI, 0.31-0.91), while chlorhexidine $0.12 \%$ and $0.2 \%$ did not have a protective effect.

\section{Efficacy depending of the patients assessed}

The previously cited meta-analysis, by Chlebicki et al. (45), Labeau et al. (43) and a more recent one by Klompas et al. (41) found a greater chlorhexidine efficacy in their subgroup analysis of cardiac surgery patients, while the effect in noncardiosurgical populations the reduction in VAP rate was non-significant $(41,43)$. Furthermore, in Klompas et al. meta-analysis, if no effect on mortality was evidenced in cardiac surgery patients, chlorhexidine increased, although non-significantly, the risk of death.

\section{Chlorhexidine drawbacks}

Several drawbacks restrain the few positive, although inconsistent, effects of chlorhexidine. The first one is its tolerance: an international randomized trial had been launched in order to evaluate, among other measures, $2 \%$ chlorhexidine efficacy (50). An unexpectedly high rate of oral mucosal lesions (29/295 patients) led to the replacement of the $2 \%$ solution by a $1 \%$ oral gel. Chlorhexidine mouthwash was however totally abandoned, again because of intolerance (50). 


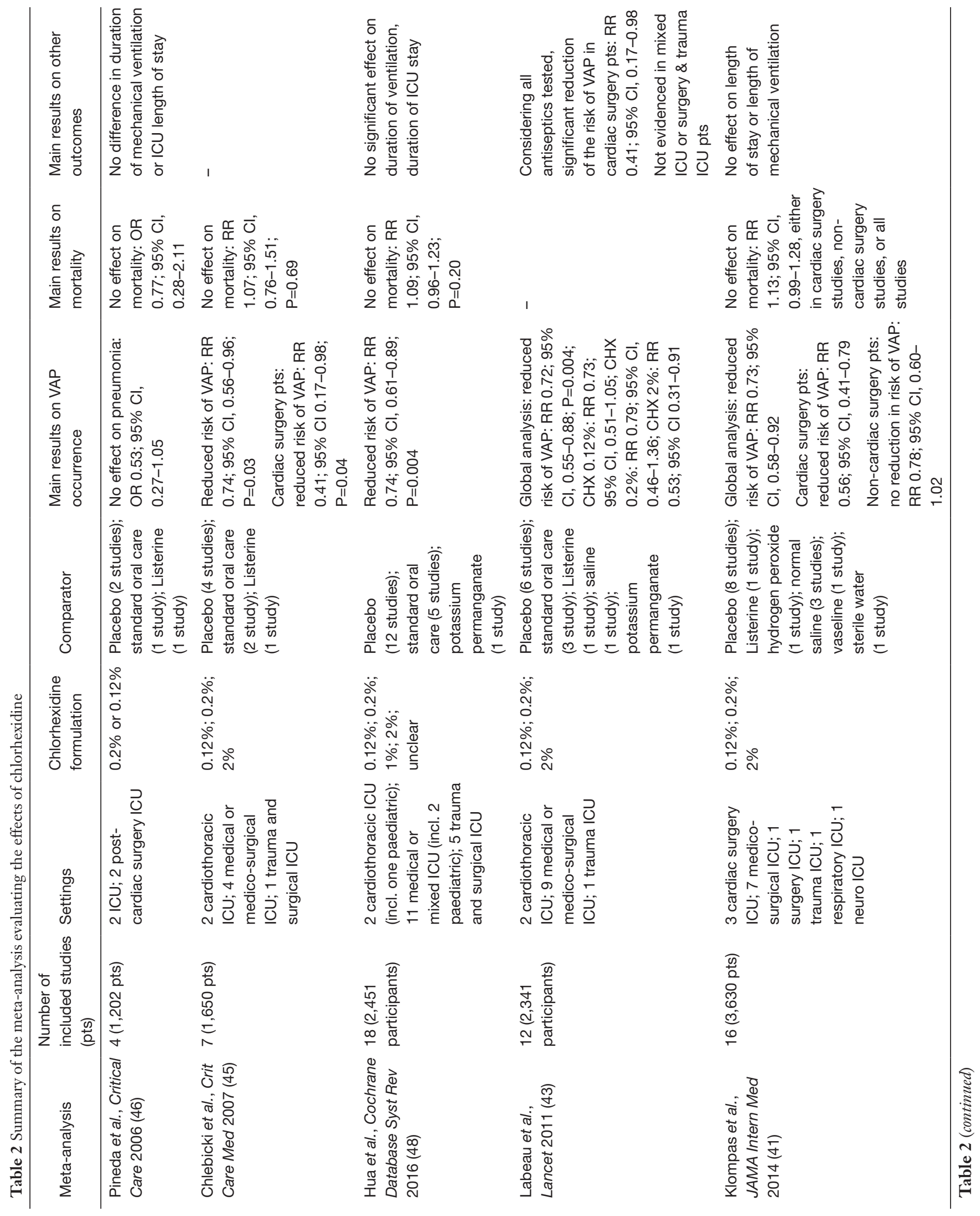




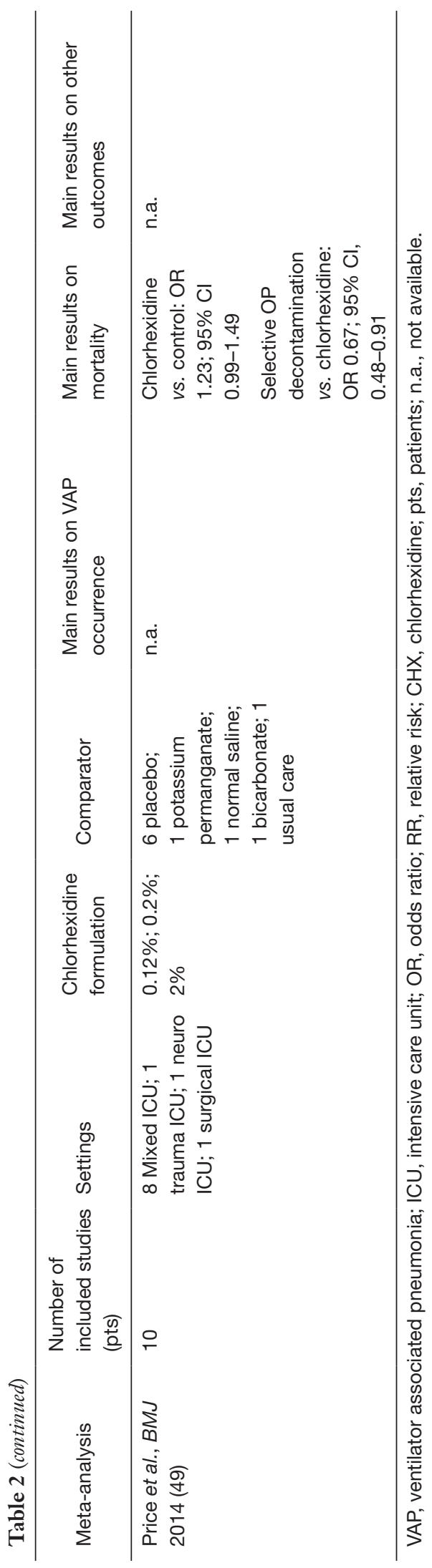

Next, two studies reported worrisome findings on chlorhexidine effect on mortality. First, a meta-analysis performed by Price et al. (49) included 11 trials (2,618 critically ill patients), and found that chlorhexidine oral care was associated with an increased mortality $(\mathrm{OR}=1.25$, 95\% CI, 1.05-1.50) compared to control or placebo. Next, in a very recently published retrospective single-centre observational study of 82,274 all-severity patients (51), $14 \%$ of the patients received chlorhexidine oral care. The authors found that an exposure to low-doses $(\leq 300 \mathrm{mg})$ was associated with an increased mortality (OR $=2.61 ; 95 \% \mathrm{CI}$, 2.32-2.92). This association was even higher in patients with a lower risk of death, while this association was not found for patients receiving mechanical ventilation, or undergoing major cardiothoracic or vascular surgery. These two studies raise questions that still have to be answered (52).

Lastly, our group studied chlorhexidine susceptibility of 260 E. coli isolates responsible for VAP (53). We showed that chlorhexidine susceptibility was reduced for $26.9 \%$ of the strains, with a significant correlation between antimicrobial and chlorhexidine resistance. These findings bring another concern to chlorhexidine efficacy.

Indeed, if chlorhexidine is ineffective not only in a clinical perspective but also too on a microbiological one, and if, in addition to that inefficacy, it holds severe adverse effects, its use is highly questionable.

Some alternative therapies are therefore urgently needed. Among those, proanthocyanidins might be of special interest.

\section{Proanthocyanidins}

Cranberry proanthocyanidins have been shown to inhibit E. coli adhesion to the urothelium (54,55). Moreover, it has been shown to decrease E. coli virulence in an in vivo model of Caenorbabditis elegans (55). Our group (56) showed that different steps leading to E. coli pneumonia could be modulated by proanthocyanidins: bacterial growth was significantly impaired by increased concentrations of proanthocyanidins; E. coli adhesion to epithelial buccal cells was significantly reduced and its protective effect on mortality was assessed and confirmed in a mouse model of pneumonia, with a significant reduction in inflammatory response (56). Furthermore, unpublished preliminary data suggest a similar effect on various other pathogens. These interesting and promising studies urge to move forward this path. 


\section{What's next for OP colonization exploration?}

More than 50 years after its first description, in a context of widespread antimicrobial resistance in GNB, a reappraisal of OP colonization composition is required. Meanwhile, further data to better administrate chlorhexidine, in terms of dosage, but also in defining the best population to target oral decontamination, are needed. Nevertheless, regarding the worrisome spreading of antimicrobial resistance, and given its link to chlorhexidine resistance, the development of alternatives to prevent and treat $\mathrm{OP}$ colonization are urgently needed.

\section{Acknowledgements}

None.

\section{Footnote}

Conflicts of Interest: The authors have no conflicts of interest to declare.

\section{References}

1. Johanson WG, Pierce AK, Sanford JP. Changing pharyngeal bacterial flora of hospitalized patients. Emergence of gram-negative bacilli. N Engl J Med 1969;281:1137-40.

2. Mackowiak PA. The normal microbial flora. N Engl J Med 1982;307:83-93.

3. Aas JA, Paster BJ, Stokes LN, et al. Defining the Normal Bacterial Flora of the Oral Cavity. J Clin Microbiol 2005;43:5721-32.

4. Belda-Ferre P, Alcaraz LD, Cabrera-Rubio R, et al. The oral metagenome in health and disease. ISME J 2012;6:46-56.

5. Preza D, Olsen I, Willumsen T, et al. Diversity and sitespecificity of the oral microflora in the elderly. Eur J Clin Microbiol Infect Dis 2009;28:1033-40.

6. Mobbs KJ, van Saene HKF, Sunderland D, et al. Oropharyngeal Gram-negative bacillary carriage in chronic obstructive pulmonary disease: relation to severity of disease. Respir Med 1999;93:540-5.

7. Vetor R, Murray CK, Mende K, et al. The use of PCR/Electrospray Ionization-Time-of-Flight-Mass Spectrometry (PCR/ESI-TOF-MS) to detect bacterial and fungal colonization in healthy military service members. BMC Infect Dis 2016;16:338.
8. Mackowiak PA, Martin RM, Jones SR, et al. Pharyngeal colonization by gram-negative bacilli in aspiration-prone persons. Arch Intern Med 1978;138:1224-7.

9. Sachs AP, van der Waaij D, Groenier KH, et al. Oropharyngeal flora in asthma and in chronic obstructive pulmonary disease. Indigenous oropharyngeal microorganisms in outpatients with asthma or chronic obstructive pulmonary disease. Am Rev Respir Dis 1993;148:1302-7.

10. Nicolle LE, McLeod J, McIntyre M, et al. Significance of pharyngeal colonization with aerobic gram-negative bacilli in elderly institutionalized men. Age Ageing 1986;15:47-52.

11. Ewan V, Perry JD, Mawson T, et al. Detecting potential respiratory pathogens in the mouths of older people in hospital. Age Ageing 2010;39:122-5.

12. Filius PMG, Gyssens IC, Kershof IM, et al. Colonization and resistance dynamics of gram-negative bacteria in patients during and after hospitalization. Antimicrob Agents Chemother 2005;49:2879-86.

13. Johanson WG Jr, Pierce AK, Sanford JP, et al. Nosocomial respiratory infections with gram-negative bacilli. The significance of colonization of the respiratory tract. Ann Intern Med 1972;77:701-6.

14. Bonten MJ, Bergmans DC, Ambergen AW, et al. Risk factors for pneumonia, and colonization of respiratory tract and stomach in mechanically ventilated ICU patients. Am J Respir Crit Care Med 1996;154:1339-46.

15. Garrouste-Orgeas M, Chevret S, Arlet G, et al. Oropharyngeal or gastric colonization and nosocomial pneumonia in adult intensive care unit patients. A prospective study based on genomic DNA analysis. Am J Respir Crit Care Med 1997;156:1647-55.

16. Donaldson SG, Azizi SQ, Dal Nogare AR. Characteristics of aerobic gram-negative bacteria colonizing critically ill patients. Am Rev Respir Dis 1991;144:202-7.

17. Ewig S, Torres A, El-Ebiary M, et al. Bacterial colonization patterns in mechanically ventilated patients with traumatic and medical head injury. Incidence, risk factors, and association with ventilator-associated pneumonia. Am J Respir Crit Care Med 1999;159:188-98.

18. Sole ML, Poalillo FE, Byers JF, et al. Bacterial growth in secretions and on suctioning equipment of orally intubated patients: a pilot study. Am J Crit Care 2002;11:141-9.

19. Scannapieco FA, Stewart EM, Mylotte JM. Colonization of dental plaque by respiratory pathogens in medical intensive care patients. Crit Care Med 1992;20:740-5.

20. Fourrier F, Duvivier B, Boutigny H, et al. Colonization 
of dental plaque: a source of nosocomial infections in intensive care unit patients. Crit Care Med 1998;26:301-8.

21. Ricard JD, Conti G, Boucherie M, et al. A European survey of nosocomial infection control and hospitalacquired pneumonia prevention practices. J Infect 2012;65:285-91.

22. Vincent JL, Rello J, Marshall J, et al. International study of the prevalence and outcomes of infection in intensive care units. JAMA 2009;302:2323-9.

23. Fuchs L, Chronaki CE, Park S, et al. ICU admission characteristics and mortality rates among elderly and very elderly patients. Intensive Care Med 2012;38:1654-61.

24. Ricard JD, Eveillard M, Martin Y, et al. Influence of tracheal suctioning systems on health care workers' gloves and equipment contamination: a comparison of closed and open systems. Am J Infect Control 2011;39:605-7.

25. Torres A, Serra-Batlles J, Ros E, et al. Pulmonary aspiration of gastric contents in patients receiving mechanical ventilation: the effect of body position. Ann Intern Med 1992;116:540-3.

26. Weist K, Pollege K, Schulz I, et al. How Many Nosocomial Infections are Associated with Cross-Transmission? A Prospective Cohort Study in A Surgical Intensive Care Unit. Infect Control Hosp Epidemiol 2002;23:127-32.

27. Ayars GH, Altman LC, Fretwell MD. Effect of decreased salivation and $\mathrm{pH}$ on the adherence of Klebsiella species to human buccal epithelial cells. Infect Immun 1982;38:179-82.

28. Abraham SN, Beachey EH, Simpson WA. Adherence of streptococcus pyogenes, Escherichia coli, and Pseudomonas aeruginosa to fibronectin-coated and uncoated epithelial cells. Infect Immun 1983;41:1261-8.

29. Dal Nogare AR, Toews GB, Pierce AK. Increased salivary elastase precedes gram-negative bacillary colonization in postoperative patients. Am Rev Respir Dis 1987;135:671-5.

30. Lukácová M, Barák I, Kazár J. Role of structural variations of polysaccharide antigens in the pathogenicity of Gramnegative bacteria. Clin Microbiol Infect 2008;14:200-6.

31. Messika J, Magdoud F, Clermont O, et al. Pathophysiology of Escherichia coli ventilator-associated pneumonia: implication of highly virulent extraintestinal pathogenic strains. Intensive Care Med 2012;38:2007-16.

32. Mosca DA, Hurst MA, So W, et al. IB-367, a Protegrin Peptide with In Vitro and In Vivo Activities against the Microflora Associated with Oral Mucositis. Antimicrob Agents Chemother 2000;44:1803-8.

33. Kokryakov VN, Harwig SS, Panyutich EA, et al.
Protegrins: leukocyte antimicrobial peptides that combine features of corticostatic defensins and tachyplesins. FEBS Lett 1993;327:231-6.

34. Giles FJ, Miller CB, Hurd DD, et al. A phase III, randomized, double-blind, placebo-controlled, multinational trial of iseganan for the prevention of oral mucositis in patients receiving stomatotoxic chemotherapy (PROMPT-CT trial). Leuk Lymphoma 2003;44:1165-72.

35. Kollef M, Pittet D, Sánchez García M, et al. A randomized double-blind trial of iseganan in prevention of ventilatorassociated pneumonia. Am J Respir Crit Care Med 2006;173:91-7.

36. Feider LL, Mitchell P, Bridges E. Oral care practices for orally intubated critically ill adults. Am J Crit Care 2010;19:175-83.

37. Rello J, Koulenti D, Blot S, et al. Oral care practices in intensive care units: a survey of 59 European ICUs. Intensive Care Med 2007;33:1066-70.

38. Milstone AM, Passaretti CL, Perl TM. Chlorhexidine: expanding the armamentarium for infection control and prevention. Clin Infect Dis 2008;46:274-81.

39. Cheung HY, Wong MM, Cheung SH, et al. Differential actions of chlorhexidine on the cell wall of Bacillus subtilis and Escherichia coli. PLoS One 2012;7:e36659.

40. Kõljalg S, Naaber P, Mikelsaar M. Antibiotic resistance as an indicator of bacterial chlorhexidine susceptibility. J Hosp Infect 2002;51:106-13.

41. Klompas M, Speck K, Howell MD, et al. Reappraisal of routine oral care with chlorhexidine gluconate for patients receiving mechanical ventilation: systematic review and meta-analysis. JAMA Intern Med 2014;174:751-61.

42. Hammond SA, Morgan JR, Russell AD. Comparative susceptibility of hospital isolates of Gram-negative bacteria to antiseptics and disinfectants. J Hosp Infect 1987;9:255-64.

43. Labeau SO, Van de Vyver K, Brusselaers N, et al. Prevention of ventilator-associated pneumonia with oral antiseptics: a systematic review and meta-analysis. Lancet 2011;11:845-54.

44. Chan EY, Ruest A, Meade MO, et al. Oral decontamination for prevention of pneumonia in mechanically ventilated adults: systematic review and meta-analysis. BMJ 2007;334:889.

45. Chlebicki MP, Safdar N. Topical chlorhexidine for prevention of ventilator-associated pneumonia: a metaanalysis. Crit Care Med 2007;35:595-602.

46. Pineda LA, Saliba RG, El Solh AA. Effect of oral decontamination with chlorhexidine on the incidence 
of nosocomial pneumonia: a meta-analysis. Crit Care 2006;10:R35.

47. Li J, Xie D, Li A, et al. Oral topical decontamination for preventing ventilator-associated pneumonia: a systematic review and meta-analysis of randomized controlled trials. J Hosp Infect 2013;84:283-93.

48. Hua F, Xie H, Worthington HV, et al. Oral hygiene care for critically ill patients to prevent ventilatorassociated pneumonia. Cochrane Database Syst Rev 2016;10:CD008367.

49. Price R, MacLennan G, Glen J, et al. Selective digestive or oropharyngeal decontamination and topical oropharyngeal chlorhexidine for prevention of death in general intensive care: systematic review and network meta-analysis. BMJ 2014;348:g2197.

50. Plantinga NL, Wittekamp BHJ, Leleu K, et al. Oral mucosal adverse events with chlorhexidine $2 \%$ mouthwash in ICU. Intensive Care Med 2016;42:620-1.

51. Deschepper M, Waegeman W, Eeckloo K, et al. Effects of chlorhexidine gluconate oral care on hospital mortality: a hospital-wide, observational cohort study. Intensive Care Med 2018;44:1017-26.

Cite this article as: Messika J, La Combe B, Ricard JD. Oropharyngeal colonization: epidemiology, treatment and ventilator-associated pneumonia prevention. Ann Transl Med 2018;6(21):426. doi: 10.21037/atm.2018.10.17
52. Ricard JD, Lisboa T. Caution for chlorhexidine gluconate use for oral care: insufficient data. Intensive Care Med 2018;44:1162-4.

53. La Combe B, Bleibtreu A, Messika J, et al. Decreased susceptibility to chlorhexidine affects a quarter of Escherichia coli isolates responsible for pneumonia in ICU patients. Intensive Care Med 2018;44:531-3.

54. Howell AB, Vorsa N, Der Marderosian A, et al. Inhibition of the adherence of P-fimbriated Escherichia coli to uroepithelial-cell surfaces by proanthocyanidin extracts from cranberries. N Engl J Med 1998;339:1085-6.

55. Lavigne JP, Bourg G, Combescure C, et al. In-vitro and in-vivo evidence of dose-dependent decrease of uropathogenic Escherichia coli virulence after consumption of commercial Vaccinium macrocarpon (cranberry) capsules. Clin Microbiol Infect 2008;14:350-5.

56. Margetis D, Roux D, Gaudry S, et al. Effects of Proanthocyanidins on Adhesion, Growth, and Virulence of Highly Virulent Extraintestinal Pathogenic Escherichia coli Argue for Its Use to Treat Oropharyngeal Colonization and Prevent Ventilator-Associated Pneumonia. Crit Care Med 2015;43:e170-8. 